\title{
Multiculturalismo, interculturalismo e decolonialidade: prolegômenos a uma pedagogia decolonial
}

\author{
Multiculturalism, interculturalism and decoloniality: \\ prolegomena to a decolonial pedagogy
}

\author{
Manuel Tavares \\ Doutor em Filosofia pela Universidade de Sevilha, US, Espanha. \\ Professor no Programa de Pós-Graduação em Educação (PPGE) \\ da Universidade Nove de Julho. São Paulo - SP - Brasil \\ tavares.lusofona@gmail.com
}

\section{Sandra Rosa Gomes}

Doutoranda em Educação no Programa de Pós-Graduação em Educação (PPGE) da Universidade Nove de Julho. Mestre em Educação. Professora no Curso de Pedagogia da mesma universidade. São Paulo - SP - Brasil

Resumo: Neste artigo refletimos sobre o processo de decolonialidade das estruturas de poder colonial, ainda dominantes nas instituições educativas, como reflexo evidente da colonialidade do poder, do saber, do gênero, da sexualidade e das relações sociais hierárquicas de dominação. As referências teóricas que nos guiam enquadram-se no modelo epistemológico pós-colonial, com enfoque específico nos estudos sobre interculturalidade, pela sua dimensão crítica, insurgente e resistente em relação aos paradigmas epistemológicos e axiológicos da modernidade ocidental e pelo seu potencial propositivo e desafiante no que diz respeito à construção de novos paradigmas que possam configurar modelos pedagógicos decoloniais, inclusivos e dissolventes da tensão conflitante entre igualdade e diferença. Consideramos que os conceitos de pedagogia, interculturalidade e decolonialidade são indissociáveis e que é nas práticas sociais, políticas e educativas que se tecem os caminhos da decolonialidade.

Palavras-chave: Decolonialidade. Interculturalidade. Pedagogias. Colonialidade. Educação.

\begin{abstract}
In this paper we reflect on the process of decoloniality of colonial power structures, still dominant in educational institutions, as an evident reflection of the coloniality of the power, of knowledge, of gender, of sexuality and of hierarchical social relations of domination. The theoretical references that guide us are framed in the postcolonial epistemological model, with a specific focus on intercultural studies, for its critical, insurgent and resistant dimension in relation to the epistemological and axiological paradigms of western modernity and its propositional and defiant potential in the which refers to the construction of new paradigms that can configure decolonial pedagogical models, inclusive and dissolving the conflicting tension between equality and difference. We consider that the concepts of pedagogy, interculturality and decoloniality are inseparable and that it is in the social, political and educational practices that weave the paths of decoloniality.
\end{abstract}

Keywords: Decoloniality. Interculturality. Pedagogies. Coloniality. Education. 


\section{Introdução}

As reflexões que nos preocupam e ocupam situam-se no âmbito da discussão sobre o processo de decolonialidade das estruturas de poder colonial, ainda dominantes nas instituições educativas, como reflexo evidente da colonialidade do poder, do saber, do gênero, da sexualidade e das relações sociais hierárquicas de dominação (1). As referências teóricas que nos guiam enquadram-se no modelo epistemológico pós-colonial, com enfoque específico nos estudos sobre interculturalidade, pela sua dimensão crítica, insurgente e resistente em relação aos paradigmas epistemológicos e axiológicos da modernidade ocidental e pelo seu potencial propositivo e desafiante no que diz respeito à construção de novos paradigmas que possam configurar modelos pedagógicos decoloniais, inclusivos e dissolventes da tensão conflitante entre igualdade e diferença. Como referido em nota (1), o conceito de colonialidade tem maior profundidade e a sua influência é mais duradoura do que o conceito de colonialismo que, do ponto de vista da sua vigência, assumiu, preferencialmente, dimensões políticas, jurídicas, administrativas e económicas. No entanto, pela sua dimensão de colonialidade atingiu as raízes mais profundas dos povos sob o seu domínio, das suas culturas, das suas línguas e das suas memórias. Apesar da "descolonização" e da "emancipação" dos povos, o colonialismo sobreviveu com todos os seus instrumentos de opressão (FANON, 2001), pela sua extensão de colonialidade, no seu imaginário, nas estruturas de poder e micropoderes, nas subjetividades, nas relações intersubjetivas, nas representações sociais e nas dimensões ontológica e epistemológica. Assistimos, por isso, a uma colonização expressa, por vezes sutil, que reprime todas as formas e modos de produção do conhecimento, irredutíveis ao paradigma dominante, de etiologia e caráter eurocêntricos e que sedimenta, na mente dos povos colonizados, um imaginário colonial. À subalternização epistemológica corresponde uma subalternidade ontológica, no sentido em que, se os saberes e memórias culturais diferentes são reduzidos a meros etnosaberes, saberes primitivos, sem legitimidade epistemológica, os povos que os possuem são, também, subalternizados, considerados primitivos ou selvagens, afinal, como não-existentes. A colonialidade do ser é, de acordo com Walsh (2006), pensada como a negação de um estatuto humano a todos os povos colonizados e que implantou problemas reais em torno da liberdade, do ser e da história dos povos submetidos a uma violência epistêmica. Estamos, assim, perante um 
verdadeiro racismo ontológico e epistemológico que hipervaloriza uma cultura e um único modelo epistêmico como fatores determinantes do desenvolvimento e do progresso.

Na perspectiva de Mignolo (2003), a expansão colonial não foi, apenas, de caráter económico e religioso, mas também das formas hegemônicas de conhecimento que contribuíram para a colonialidade do saber. Construiu-se, assim, uma geopolítica do conhecimento, cujo epicentro e lógica de pensamento se localizam na Europa.

A partir de alguns pressupostos anteriormente expressos, defendemos que os diversos discursos históricos e educativos foram construídos a partir da modernidade europeia e pelo silenciamento e esquecimento das diversas narrativas dos povos subjugados. Nesta linha de raciocínio, as diversas correntes do pensamento pedagógico, que se impuseram na Europa e na América Latina, estão feridas por múltiplos silenciamentos.

Perante a afirmação de diversas culturas nos cenários públicos, ampliada pelas migrações contemporâneas, dissolvem-se, cada vez mais, as fronteiras geográficas mas agudizam-se as fronteiras culturais. A estes cenários de existência de culturas diferentes se costuma chamar multiculturalismo. As sociedades contemporâneas são, assim, multiculturais, resultantes de uma configuração social onde coexistem culturas originárias dos diversos cantos do mundo. Imaginariamente, este seria o cenário social ideal de coexistência pacífica e diálogo entre culturas a partir do princípio do respeito pelos saberes e conhecimentos diferentes. Teriam as sociedades e os seres humanos dado um salto qualitativo no sentido da abertura ao outro, aprendizagem mútua, completude, respeito pela dignidade dos povos diferentes e das suas culturas. Mera especulação. Imaginariamente, seria também, o cenário ideal de uma escola que promove o diálogo intercultural. A realidade, todavia, é bem diferente. Como refere Candau (2011, p. 241),

[. . . ] a cultura escolar dominante em nossas instituições educativas, construída fundamentalmente a partir da matriz político-social e epistemológica da modernidade, prioriza o comum, o uniforme, o homogêneo, considerados como elementos constitutivos do universal. Nesta ótica, as diferenças são ignoradas ou consideradas um "problema" a resolver. 
Os conflitos, guerras e formas diversas de violência, no nosso pequeno mundo, resultam, não apenas da cobiça por matérias-primas existentes em diversos espaços geográficos e da obsessão patológica pela exploração do outro e pela acumulação de capital, mas de uma intolerância estrutural e ausência de respeito absoluto pelas diferenças e pela dignidade humana. Diríamos que a educação é o caminho, a porta de saída dos becos que enclausuram a humanidade no individualismo e no egocentrismo patológicos, mas uma outra educação, outras pedagogias, outras instituições, profunda e radicalmente democráticas. Refletiremos, neste texto, sobre todos os aspectos aqui assinalados, ainda envoltos pelo véu da ignorância a que os processos de colonização e colonialidade global têm conduzido o nosso mundo.

\section{Multiculturalismo: um conceito equívoco}

As sociedades contemporâneas são, indubitavelmente, sociedades multiculturais. O multiculturalismo não é um fenômeno recente. As culturas, ao longo da história, sempre tiveram contatos entre si, gerando fenómenos de hibridação (2) intercultural. Como assinala Canclini (2008), já não basta dizer que não há identidades que se caracterizam por essências estáveis e a-históricas, nem entendê-las como as formas em que as comunidades se imaginam e constroem narrativas sobre as suas origens e histórias. Num mundo tão fluidamente interconectado, as sedimentações identitárias, organizadas em conjuntos históricos, mais ou menos estáveis, se reestruturam, dando lugar a conjuntos inter-étnicos, transclassistas e transnacionais.

O fenômeno das migrações e das populações refugiadas, fenômeno crescente no mundo inteiro, por razões diversas, para além de gerar múltiplos problemas sociais e humanitários, constitui um enorme desafio no que diz respeito à reconfiguração social decorrente da "inclusão" de povos e culturas diferentes.

As discussões e debates que acontecem no mundo académico, e fora dele, acerca do multiculturalismo, justificam-se pelo fato de haver existido, durante séculos, a ausência de qualquer referência à diversidade cultural e o multiculturalismo, que sempre existiu, haver sido ocultado pelo monoculturalismo. As diversas culturas, muitas delas milenares, foram, até certo ponto, "reconhecidas" pelo colonialismo, apesar do "pecado original da conquista" (3): as suas tradi- 
ções, normas diferentes, hierarquias, cultos e rituais religiosos, como é o caso de determinadas culturas indígenas da América Latina e algumas tribos africanas. Por isso, a primeira forma de multiculturalismo foi o colonial que, embora "reconhecendo" as culturas dos povos originários, as considerou inferiores e as submeteu, violentamente, ao domínio da cultura dominante suprimindo muitos traços culturais identitários. É, por isso, "um multiculturalismo que, de facto, não permite que haja um reconhecimento efetivo de outras culturas." (SANTOS, 2003, p. 12). Esse multiculturalismo conservador, regulatório, não admite, por exemplo, a etnicidade - conceito aplicado apenas aos que não são brancos - nem a incompletude da cultura ocidental. A arrogância etnocêntrica traduz-se na ideia de que o Ocidente produziu aquilo que há de melhor, desde a ciência à técnica, aos sistemas políticos e jurídicos, a escrita, as línguas, a religião judaico-cristã e a própria história que não se compara à a-historicidade dos povos colonizados. $\mathrm{O}$ Ocidente produziu as certezas em torno das quais giram as grandes incertezas da vida. Os povos originários não têm angústias (estas, são invenção do Ocidente). Nada melhor do que transmitir-lhes também essa doença civilizacional e as receitas prontas para todas as insatisfações existenciais na subida dos degraus da vida. Os colonizadores, ao defenderem que os povos sob o domínio colonial não têm escrita nem história, legitimam o processo de colonização. Por estas razões essenciais, a cultura ocidental torna-se universal e resume em si mesma tudo o que de melhor foi dito e pensado no mundo. (SANTOS, 2003). Esta arrogância cultural e complexo de superioridade define, em síntese, o monoculturalismo e "legitima" os seus ideais expansionistas e suas políticas assimilacionistas. A forma de multiculturalismo que defende torna-se descritiva e legitimadora do etnocentrismo europeu-ocidental e, afinal, do monoculturalismo. $\mathrm{O}$ autor refere, ainda, o multiculturalismo emancipatório, pós-colonial, que assenta numa tensão dinâmica entre política de igualdade e política da diferença. A política da igualdade está baseada na luta contra as diferenciações de classe, mas deixou na penumbra outras formas de discriminação étnicas, de gênero, orientação sexual, etárias e outras. Foi a emergência das lutas contra todas as formas de discriminação que instituiu as políticas da diferença. Estamos, refere o autor, perante um outro modelo de multiculturalismo, de caráter progressista que procura colocar na mesma equação a tensão existente entre políticas de igualdade e políticas da diferença. (SANTOS, 2003) 
Para o jamaicano Stuart Hall (2010, p. 583), cujo pensamento é incontornável no âmbito dos estudos culturais, o multiculturalismo é entendido como o conjunto de

[...] estratégias e políticas adotadas para governar ou administrar os problemas da diversidade e a multiplicidade que existem nas sociedades multiculturais" com a sua variedade de distinções: conservador, liberal, pluralista, comercial, corporativa e criticaradical. (4)

O autor também marca um traço distintivo entre as diferentes formas de multiculturalismo. A título de exemplo, refere:

O multiculturalismo conservador segue Hume (GOLDBERG, 1994), que enfatiza a assimilação da diferença às tradições e costumes da maioria. O multiculturalismo liberal procura integrar diferentes grupos culturais tão rapidamente quanto possível dentro do estabelecido por uma cidadania individual universal, que só tolera certas práticas culturais peculiares no domínio privado. O multiculturalismo pluralista aprova formalmente as diferenças entre os grupos ao longo das linhas culturais e concede direitos diferentes para diferentes grupos e comunidades dentro de uma comunidade política ou comunitária. O multiculturalismo comercial assume que, se o mercado reconhece a diversidade de indivíduos de diferentes comunidades, então os problemas da diferença cultural serão resolvidos através do consumo privado, sem qualquer necessidade de uma redistribuição de poder e recursos. O multiculturalismo empresarial (público ou privado) busca "administrar" diferenças culturais das minorias em juros ou centro de lucro. o multiculturalismo crítico ou "revolucionário" destaca o poder, o privilégio, a hierarquia de opressão e os movimentos de resistência (McLAREN, 1997). Procura ser 'insurgente, polifónico, heteroglóssico e anti-fundacional' (GOLDBERG, 1994). E assim por diante (HALL, 2010, p. 584). (5) 
O texto refere vários tipos de multiculturalismo. Todavia, nenhum deles aponta para o diálogo entre a diversidade e diferença culturais. O próprio multiculturalismo crítico, pelo que se pode inferir do texto, é apenas uma crítica e uma resistência ao modo de funcionamento da sociedade denominada "multicultural".

Ao dialogarmos com o pensamento de Boaventura Santos (2013), teórico contemporâneo, nos circuitos do tempo e do espaço, reconhecido em todo o mundo por sua contribuição teórica que mobiliza a academia, pelos seus projetos pluralistas, apontados à emancipação social, defende, principalmente, a ideia de que "uma das formas de pensar a globalização, é pensar em modos alternativos de pensar, é pensar em culturas alternativas, em conhecimentos alternativos, os quais só podem, naturalmente, ser reconhecidos se tomarmos uma atitude de multiculturalismo ativo e progressista" (p. 11). Discordamos do conceito de "alternativa", por considerarmos que o seu significado habitual carrega consigo o sentido de subalternidade, não sendo a alternativa colocada em pé de igualdade relativamente ao percurso, pensamento ou conhecimento dominantes. Preferimos, por isso, adotar expressões como "outras formas de pensar", "outros conhecimentos", "outras culturas", ou, ainda, pensamentos, culturas, conhecimentos contra-hegemônicos. O autor refere-se ao multiculturalismo como um "conceito contestado" do seguinte modo:

A expressão multiculturalismo designa, originalmente, a coexistência de formas culturais ou de grupos caracterizados por culturas diferentes no seio de sociedades modernas. Rapidamente, contudo, o termo se tornou um modo de descrever as diferenças culturais num contexto transnacional e global. Existem diferentes noções de multiculturalismo, nem todas de sentido emancipatório. O termo apresenta as mesmas dificuldades e potencialidades do conceito de cultura, um conceito central das humanidades e das ciências sociais e que, nas últimas décadas, se tornou um terreno explícito de lutas políticas. (SANTOS, 2004, p. 20).

Ainda na linha de pensamento de Boaventura Santos (2004, p. 25), podemos explorar um pouco mais o multiculturalismo emancipatório, já referido anteriormente, cuja expressão "pode continuar a ser associada a conteúdos e projetos 
emancipatórios e contra-hegemônicos", baseando-se "no reconhecimento da diferença e do direito à diferença e da coexistência ou construção de uma vida em comum para além de diferenças de vários tipos."

Catherine Walsh (2005, p. 05), coordenadora do programa de doutorado em Estudos Culturais Latino-Americanos da Universidad Simon Bolivar, em Quito, no Equador, considera, na mesma linha de Santos (2004), que "o multiculturalismoé, essencialmente, um termo descritivo. Normalmente, ele refere-se à multiplicidade de culturas que existem dentro de um determinado espaço, seja local, regional, nacional ou internacional, sem necessariamente haver uma relação entre eles." Para a autora, essa perspectiva multicultural, ocorre

no contexto de países ocidentais, como os Estados Unidos, onde as minorias nacionais (negros e índios) coexistem com vários grupos de imigrantes, minorias involuntárias como porto-riquenhos e chicanos, e brancos, todos descendentes de outros países, principalmente os europeus; ou, como na Europa, onde a imigração foi recentemente ampliada. (6)

Conforme foi possível observar, o conceito de multiculturalismo é polissêmico e pode gerar equívocos se utilizado em abstrato, sem quaisquer referências e contextualizações. Como refere Candau (2008) "entre igualdade e diferença, isto é, da passagem da afirmação da igualdade ou da diferença para a da igualdade na diferença" (CANDAU, 2008, p. 49), seguramente são incontáveis e abrangentes as opiniões ou pontos de vista sobre as vertentes multiculturais. Na linha histórica das múltiplas influências na formação de uma cultura e construção das identidades culturais, nenhuma cultura é monocultural, o que significa que, consideradas isoladamente, todas elas são incompletas, tornando-se necessário, como refere Santos, (1997, p. 114), "aumentar a consciência de incompletude cultural [que] é uma das tarefas prévias à construção de uma concepção emancipadora e multicultural dos direitos humanos." Do ponto de vista da cidadania, da afirmação da liberdade e igualdade entre todos os seres humanos e culturas, da consolidação da democracia e das respectivas instituições democráticas, há que recusar todas as formas de apartheid. Defender, por exemplo, que cada cultura ou cada grupo social é responsável pela sua emancipação, é uma forma de apartheid social. As lutas pela igualdade, respeito pelas diferenças e pela liberdade são conjuntas e 
não podem confinar-se a ghettos. A separação gera desigualdades, injustiças e discriminação.

\section{Interculturalidade crítica e o processo de decolonialidade}

No que se refere à interculturalidade, Walsh (2012, p. 62) afirma que pensar a Interculturalidade a partir do "contexto europeu não é o mesmo que pensá-la na América do Sul, onde as aspirações de dominação do mundo, o surgimento do mercado global e a imposição de modernidade e seu outro lado oculto, a colonialidade, tomou forma prática e sentido.’

Para Walsh (2005, p. 09), autora que desenvolve importantes trabalhos sobre a temática, "a interculturalidade é diferente no que diz respeito a complexas relações, negociações e trocas culturais, e procura desenvolver uma interação entre pessoas, conhecimentos e práticas culturalmente diferentes”. Sua perspectiva intercultural "não pode ser reduzida a uma simples mistura, ou fusão, combinação híbrida de elementos, tradições, características ou práticas culturalmente diferentes". (Id. Ibid.). Acredita, ainda, que é incontestável compreender a interculturalidade em suas diversas dimensões e sugere uma importante discussão e análise profunda da atual realidade das sociedades e, sem esgotar o objeto, busca resumir, de forma concreta, o que se entende por interculturalidade (WALSH, 2005, p. 10-11):

- Um processo dinâmico e permanente de relação, comunicação e aprendizagem entre culturas em condições de respeito, legitimidade mútua, simetria e igualdade;

- Um intercâmbio que se constrói entre pessoas, conhecimentos, saberes e práticas culturalmente diferentes, buscando desenvolver um novo sentido entre elas na sua diferença;

- Um espaço de negociação e de tradução onde as desigualdades sociais, econômicas e políticas, e as relações e os conflitos de poder da sociedade não são mantidos ocultos e sim reconhecidos e confrontados.

- Uma tarefa social e política que interpela o conjunto da sociedade, que parte de práticas e ações sociais concretas e conscientes e tenta criar modos de responsabilidade e solidariedade.

- Uma meta a alcançar. (7) 
Nestes contextos, entendemos que os desafios que se colocam aos professores e educadores são enormes, em termos de formação, e abrem horizontes epistemológicos e axiológicos, impensáveis no âmbito do tradicional paradigma de formação docente. A formação de professores, no âmbito da interculturalidade, implica um novo modelo de formação docente que leve em consideração as culturas e saberes decorrentes da diversidade e da diferença cultural. Por outro lado, uma formação para a interculturalidade supõe novas linguagens, novos conceitos e novos paradigmas na construção do conhecimento e novas estratégias pedagógicas e didáticas.

Nas sociedades contemporâneas, sobretudo as que se situam na América Latina, sociedades verdadeiramente multiculturais, a interculturalidade assume, de fato, uma dimensão prática entendendo por essa dimensão o diálogo que se estabelece entre as diversas culturas. É, por isso, um projeto político que transcende a dimensão educativa para pensar a construção de sociedades diferentes, o que não é possível sem a esfera educativa. Os desafios educativos na América Latina, de acordo com a perspectiva de Raul Fournet-Bittencourt (2004) passa pela proposta de um diálogo intercultural como caminho para uma filosofia da alteridade em que os outros são reconhecidos nas suas identidades e tradições e a partir dos seus lugares de enunciação. Este é, de acordo com o autor, o percurso necessário para dissolver as hegemonias políticas, filosóficas, epistemológicas e axiológicas do Ocidente e iniciar um processo decolonial, passo necessário para uma filosofia da libertação e para um outro modelo de participação social e de democracia.

Os fenômenos da multiculturalidade e da interculturalidade constituem importantes fatores de mudança no contexto nacional e internacional, quer seja a nível individual, quer coletivo. É importante considerar que a globalização ou colonialidade global, os fluxos migratórios e os refugiados por motivos de guerra (da Síria, por ex.,) aumentaram progressivamente nas últimas décadas, o que possibilitou outras formas de contato entre as culturas e, simultaneamente, a convivência entre diferentes modos de vida e de representação do mundo. Os processos migratórios têm contribuído para o que podemos classificar de multiculturalismo nas sociedades e nas instituições educativas, bem como para a partilha e coexistência de tradições culturais diferentes, de competências e de saberes. Todavia, como referimos anteriormente, o fato de as sociedades serem cada vez mais multiculturais não significa que sejam interculturais. O 
multiculturalismo, tal como é considerado nas sociedades contemporâneas do Ocidente é meramente descritivo, funcional e contribui para a legitimação do etnocentrismo ocidental.

O conceito de interculturalidade, que assumimos neste texto, aponta para o reconhecimento de e respeito por todas as culturas, sem hierarquia entre elas. $\mathrm{Na}$ América Latina, a interculturalidade tem um significado específico: "ela está ligada às geopolíticas do espaço e do lugar, às lutas históricas e atuais dos povos indígenas e negros e à construção de projetos sociais, culturais, políticos, éticos e epistémicos, orientados para a transformação social e para a descolonização". (WALSH, 2006, p. 21). Mais do que um conceito que faz o apelo e promove a interação e comunicação entre culturas e saberes, o significado que lhe é atribuído assinala a necessidade de construção de outros modelos de conhecimento e de produção epistémica, de outros modelos educativos e pedagógicos, de uma outra prática política, de um outro poder social e de uma outra sociedade, o que supõe e implica o desvio das formas de poder dominantes e dos paradigmas sociais e epistemológicos de caráter eurocêntrico e colonial.

A vantagem do conceito de interculturalidade é que a sua origem não está nos meios académicos, mas nas comunidades indígenas e na diferença colonial (MIGNOLO, 2003), que o tomam como um princípio ideológico transformador da realidade social e comunicacional. Por não ter a sua origem nos centros geopolíticos de produção do conhecimento - o mundo académico - não está impregnado de eurocentrismo nem de princípios que o norte global, tradicionalmente, impõe ao sul. Não traz consigo essa máquina infernal das certezas prontas a servir. É, por isso, pensamos, um conceito subversivo, resistente e insurgente. Consideramos que sem os pressupostos assinalados não haverá qualquer possibilidade de decolonialidade do poder e do saber e de um diálogo inter-epistémico.

A interculturalidade implica, por isso, o reconhecimento e o respeito das e pelas diferenças culturais, fator fundamental do diálogo entre as culturas. Catherine Walsh $(2012,2013,2014,2015)$ destacou três perspectivas para o conceito de interculturalidade: relacional, funcional e crítica. Seguindo o pensamento da autora, a interculturalidade relacional é vista como o intercâmbio cultural preestabelecido entre os diferentes grupos étnico-culturais que convivem no mesmo espaço geográfico. Dessa maneira, pressupõe-se que sempre existiu a interculturalidade nos países da América Latina, em razão da 
formação étnico-cultural diversa; já a interculturalidade funcional aposta no reconhecimento da diversidade sociocultural e nas diferenças existentes, tolerando as diferentes expressões socioculturais, visando a integração dos grupos considerados diferentes no interior das estruturas sociais existentes. Esta forma de interculturalidade legitima o monoculturalismo e a sua "suposta" superioridade. Pelo contrário, na interculturalidade crítica entende-se que as diferenças se constroem dentro de uma matriz de poder colonial, racializado e hierarquizado, assentes em espaços de questionamentos a respeito dessas relações de poder, podendo ser entendida também como projeto político, social, epistêmico e ético, que aposta, não apenas nas relações culturais, mas, sobretudo, no entendimento das estruturas e dispositivos de poder que mantêm a desigualdade, a inferiorização, a racialização e a discriminação. A título de exemplo, as escolas e universidades, que são organizacionalmente constituídas por estruturas de dominação, por poderes e micropoderes, poderão impedir a interculturalidade. Esta deverá ser acompanhada por um processo de decolonialidade das estruturas de poder "de longa duração". Em síntese, a interculturalidade, enquanto diálogo entre as diversas culturas e saberes, só é possível pela dissolução das estruturas coloniais de longa duração, indissoluvelmente ligada ao processo de decolonialidade e pela construção dos espaços escolares em espaços de aprendizagem e exercício democrático. Pensar um novo modelo educativo e novos modelos pedagógicos implica, por exemplo, a dissolução do dualismo sujeito-objeto em que assenta a prática pedagógica tradicional; o professor transmissor e reprodutor de conhecimento deverá ser um mestre de orientação de pesquisa, exigente e rigoroso no que diz respeito aos métodos, metodologias e fundamentações epistemológicas. Promotor do espírito crítico, da capacidade argumentativa, dos argumentos lógicos que sustentam uma argumentação e da construção de competências hermenêuticas. O espaço escolar deve transformar-se em espaço de múltiplas aprendizagens, cooperativas e solidárias, de exercício crítico da democracia, de diálogo intercultural, de aprendizagem da liberdade e de uma cidadania emancipatória e participante.

Abordaremos, a seguir, o que consideramos ser uma aproximação a uma pedagogia ou a pedagogias decoloniais, seus pressupostos teóricos e políticos e as possíveis relações entre interculturalidade, o pedagógico e o decolonial. 


\section{Aproximação a pedagogias de caráter decolonial}

Nos processos educativos, professores e educadores são agentes fundamentais, tanto das mudanças, quanto do conformismo, reprodução e perpetuação do status quo. Como referia Freire (1987), o oposto da intervenção é acomodação e adaptação a uma realidade, sem questionamento. Aliás, os professores, sobretudo os que silenciosamente se acomodam, são fundamentais para a manutenção dos projetos hegemônicos, tornando-se, muitas vezes sem consciência, cúmplices da perpetuação do sistema e dos seus propósitos repressivos. Esta atitude compassiva por parte de agentes fundamentais da educação, não só legitima como reforça o modelo escolar dominante. Não basta mudar a gramática da escola, é necessário descolonizar as próprias mentes dos professores para alterar, também, a semântica da escola e das instituições educativas.

A ausência de uma formação inicial e continuada de professores, que tenha em consideração as novas realidades trazidas pela colonialidade global, pelas suas estratégias de afirmação global e local, de imposição de uma cultura única, em sociedades multiculturais, tem conduzido à continuidade de uma docência reprodutivista e acrítica. O mundo mudou, mas os modelos de formação de professores e de educação não se alteraram. De salientar a importância da regulação jurídica relativamente à problemática da inclusão no sistema de ensino de parte da população que não tinha, historicamente, acesso à educação; de salientar, também, a regulação jurídica da obrigatoriedade do ensino da história e das culturas afro-brasileiras e indígenas. Apesar da importância da lei, grande parte dos professores desconhece a obrigatoriedade da sua implementação e, mais grave ainda, quando conhece, não a perspectiva como um meio de combate ao racismo e à discriminação. Felizmente, nos últimos anos, no Brasil e no mundo, os debates sobre as relações entre diferenças culturais, multiculturalismo, interculturalismo e educação têm-se intensificado e aprofundado. Estes debates e produções académicas têm gerado movimentos de exigência de novos modelos pedagógicos que respondam às problemáticas da diversidade cultural e da inclusão educativa e social. A tensão entre igualdade e diferença, de que nos fala Boaventura Santos (2003), abre perspectivas para abordagens pedagógicas multiculturais e interculturais críticas. Apesar de o colonialismo preceder a colonialidade, esta sobrevive ao colonialismo e manifesta-se, como referimos anteriormente, na cultura, no conhecimento transmitido, no imaginário dos povos, nas produções simbólicas, 
nas manifestações subjetivas dado que, pela colonialidade, se construiu a subjetividade dos povos colonizados. Como refere Maldonado-Torres (2007, p. 131),

[...] a colonialidade mantém-se viva em textos didáticos, nos critérios para o bom trabalho académico, na cultura, no sentido comum, na auto-imagem dos povos, nas aspirações dos sujeitos e em muitos outros aspectos de nossa experiência moderna. Neste sentido, respiramos a colonialidade na modernidade cotidianamente.

Uma pedagogia de caráter eurocêntrico se mantém por interferência da colonialidade do poder, das mentes e do conhecimento. A hegemonia epistémica europeia ocidental, que se mantém e se traduz numa espécie de racismo epistémico, não admite outras lógicas, racionalidades diferentes e formas diferentes de expressão do pensamento. Esta hegemonia espelha-se nas pedagogias e nas didáticas, privilegiando um ensino reprodutor de conhecimento e a "autoridade" do professor que se impõe, muitas vezes, não pelo saber, mas pelo autoritarismo, forma primária de violência. O conceito de decolonial, ligado à pedagogia, revela, em primeiro lugar, um horizonte de esperança nas mudanças necessárias a realizar no sistema educativo e nas relações pedagógicas; em segundo lugar, a relação entre os dois conceitos sugere resistência, insurgência e transgressão relativamente a um sistema educativo e seu correspondente pedagógico de caráter monocultural, patriarcal, antropocêntrico e colonial. Ao sistema colonial global, uniformizante, que adota uma pedagogia da crueldade para subsistir e se expandir, deve corresponder uma pedagogia da resistência e da insurgência, uma pedagogia da esperança. Freire (2015) referia que não há prática social mais política do que a prática pedagógica, a prática educativa. Nesta perspectiva, o professor comprometido com a decolonialidade amplia o seu compromisso com o social e o político, com as lutas sociais, ontológicas e epistémicas, tendo em vista a emancipação dos povos. Os espaços pedagógicos ultrapassam largamente as paredes dos edifícios e o âmbito das instituições escolares e educativas. Ser pedagogo é estar com e ao lado dos povos oprimidos na luta contra todas as formas de opressão, discriminação e exclusão. Ser político é participar da vida, comprometido com as grandes questões sociais, sair das posições confortáveis do "nem sim nem não", de ausência de opinião e de posicionamento social, contribuir para tornar os homens e mulheres 
mais conscientes das suas potencialidades, mais críticos e, por que não, mais felizes. Ser político é, afinal, ter um pensamento, partilhar com os outros, recusar o fundamentalismo totalitário das certezas e ser capaz de assumir a volatilidade das incertezas.

Afirmamos, anteriormente, no tópico sobre interculturalidade crítica, que este conceito é indissociável do processo de decolonialidade. Esclareçamos melhor esta relação, acrescentando-lhe o conceito de pedagogia. Gostaríamos de pensar os conceitos de pedagogia e pedagógico para além da sua dimensão institucional e escolar, atribuindo-lhe uma versatilidade desafiante relativamente à racionalidade moderna e à dimensão instrumental de ensino e transmissão de saber e em total oposição a essa "pedagogia da crueldade", reprodutora e perpetuadora dos sistemas educativos conservadores e de caráter colonial e neocolonial. Uma pedagogia corrosiva que se pratica a partir do local, das memórias coletivas, aproveitando as fissuras e fraturas do sistema, desvelando e revelando as suas debilidades e contradições. Decolonizar é pensar de outro modo, contrariando a lógica e racionalidade dominantes, inscritas, historicamente, nas estruturas mentais colonizadas e nas estruturas coloniais sistémicas das instituições sociais e educacionais. O momento histórico, conjuntural, por que passa a maior parte dos países da América Latina, resubordinada ao ultraneoliberalismo colonial, é bem difícil para as formas críticas de pensar e agir. Numa fase histórica de regresso da Casa Grande, sugerem-se, por isso, pedagogias que promovam o pensamento crítico, que possibilitem a construção de modos diferentes de pensar, ser e existir, que animem o pensar a partir de e com os movimentos resistentes da sociedade e que tenham projetos e horizontes decoloniais. Como afirma Catherine Walsh (2017, p. 14),

Para mí, las pedagogías decoloniales son todo esto: son los procesos y las prácticas que animan, provocan y hacen el caminar, luchar, preguntar y sembrar de vida en estos tiempos de guerra-muerte en que la colonialidad se reconstituye en el capitalismo global.

Pedagogias que ultrapassam as instituições educativas, mas que as incluem, que se forjam no interior das lutas sociais e que constituem estratégias metodológicas imprescindíveis para a construção de modelos epistemológicos outros, decorrentes do pluralismo cultural existente nas sociedades e instituições contem- 
porâneas. Que convocam os saberes subalternizados, produzidos nas práticas de marginalização e de resistência e lhes conferem legitimidade reflexiva, interpelando e desafiando os saberes dominantes. Pedagogias que devem afirmar-se na sua dimensão ontológica, pelo reconhecimento e afirmação da dignificação de todo o ser humano, contra todas as formas de discriminação; pedagogias que irradiam princípios éticos de respeito, justiça, emancipação e liberdade e que traçam percursos para ler criticamente o mundo e aquele que não foi lido e intervir na reinvenção social. A leitura do mundo, de que nos fala Paulo Freire (2006), precede a leitura da palavra e esta promove uma releitura crítica a partir do processo de conscientização. As novas pedagogias interculturais e decoloniais têm a responsabilidade de ler o mundo, como já referido, que ainda não foi lido, a partir da diferença colonial de que nos fala Mignolo (8). As lutas sociais, bem como as instituições educacionais são cenários pedagógicos de aprendizagem solidária, de diálogo, de reflexão e ação. A relação entre o pedagógico, o intercultural e o decolonial parece-nos ser indissociável para a dissolução das estruturas coloniais do poder, do conhecimento e do ser e para a abertura de horizontes de esperança na construção de uma sociedade de justiça social e de humanização de todos os seres humanos, independentemente da sua cor da pele, do gênero, orientação sexual, política, religiosa e cultura.

\section{Considerações finais e desafios}

Uma das mais importantes mudanças sustentadas pelo capitalismo ultraneoliberal contemporâneo, de características eminentemente financeiras e especulativas, tem sido a importância atribuída ao conhecimento, não como fator de promoção da justiça social e cognitiva, mas, sobretudo, como capital, elemento produtivo e competitivo e fator de exploração. Esta realidade conduz à universalização das políticas a partir dos centros de poder internacionais, onde são definidas as agendas globalmente estruturadas, fundamentadas na retórica da objetividade, da quantificação e na ideologia do progresso (TEODORO, 2003; DALE, 2001), impedindo a afirmação das diferenças entre países e culturas. Prevalece uma visão meramente instrumental da educação que prioriza resultados quantitativos, decorrentes de parâmetros e critérios predefinidos - varáveis comparativas - menosprezando os contextos históricos de cada país, as suas culturas e ritmos 
de desenvolvimento científico-tecnológico, econômico e social. Impede, ainda, a autonomia e independência dos Estados em definir as suas políticas em função dos seus contextos sociais e conjunturais e das suas tradições e tem implicações negativas na autonomia das universidades, no modelo de conhecimento produzido e na qualidade das publicações acadêmicas. Constitui, assim, um obstáculo à mudança de rumo da globalização hegemônica, dos seus fundamentos políticos e epistemológicos e da uniformização do conhecimento que impõe. Estamos, por isso, no âmbito da colonialidade global, no paroxismo da razão instrumental, definida por Horkheimer e pela teoria crítica, como instrumento de dominação, poder e exploração. Perdeu o seu caráter emancipatório para se tornar um instrumento de dominação, exploração e mistificação da realidade, excluindo todas as formas de saber que caracterizam as culturas locais e as memórias coletivas. Cremos que estamos longe da dissolução desta ordem global e do seu projeto civilizatório, opressor e excludente. A continuidade de uma narrativa histórica imperialista, produzida pelo Ocidente e reinventada na era da colonialidade global, aprofunda a falsificação e o esquecimento da verdade histórica, do lado oculto da história. Sugerimos, neste texto, a partir das propostas de Walsh (2012, 2013, 2014, 2015), Mignolo (2003) e Quijano (2007), pedagogias interculturais e decoloniais, insurgentes e resistentes, construídas em espaços, práticas e contextos marginalizados, que convocam conhecimentos também marginalizados ao longo da história, conhecimentos produzidos pela diferença colonial, que possam desestabilizar e denunciar as práticas, estruturas e conhecimentos hegemônicos de caráter opressivo. Pedagogias interculturais e decoloniais que deverão ter os seus reflexos nas instituições educativas como resultado das práticas pedagógicas construídas em espaços e cenários sociais de luta e resistência. Na conjuntura atual, ganha cada vez mais sentido a proposta pedagógica de conscientização de Freire. A conscientização relativamente à situação de opressão é, sem dúvida, um pressuposto fundamental para a emancipação e libertação, só possíveis no âmbito de propostas políticas e educativas decoloniais, mas também de práticas políticas e epistémicas insurgentes e decoloniais à revelia dos modelos académicos institucionalizados, de etiologia eurocêntrica e estadunidense, com as suas propostas de uma lógica e racionalidade legitimadoras de uma tradicional e colonial geopolítica do conhecimento. Uma pedagogia orientada por uma ética decolonial radicalmente democrática, que reconheça o outro nas suas dimensões ontológica, cultural e epistemológica como fatores incontornáveis de humanização. Colocar a questão 
ontológica, na anterioridade das questões cultural e epistemológica, parece-nos ser fundamental e prioritário. Se olharmos à nossa volta, a inferiorização do outro tem como pressuposto as questões de raça e género, categorias coloniais por excelência, construídas e impostas ao longo da história. A inferiorização do negro, do índio, da mulher, da mulher negra ou índia não está relacionada, em primeiro lugar, com a sua cultura ou identidade, mas parte de premissas biológicas que se expandem na condição étnico-racional originária, ou seja, na sua condição ontológico-existencial. Sendo assim, a relação entre o pedagógico e o decolonial ultrapassa o domínio cultural e intercultural para recuar à dimensão biológica onde, inexoravelmente, começa por se exercer a colonialidade. O desafio da decolonialidade exige permanentes teorizações, reflexões, individuais e coletivas, a partir das práticas políticas, sociais e educativas e ensaiar novos caminhos pedagógicos de dimensão decolonial, constitui, não apenas o resultado de uma teoria da decolonialidade, mas exige uma prática comprometida.

Neste texto, mais do que a abertura de caminhos, aliás propostos por outros autores (Walsh (2012, 2013, 2014, 2015), Mignolo (2003), Quijano (2007), Fanon (2001), Freire (1987, 2006, 2015) que clarificam, analiticamente, a pluridimensionalidade da opressão e das formas diversas de exclusão social em sociedades "supostamente" democráticas, procuramos bater a portas que se possam abrir, na esperança militante de uma outra educação e de um mundo mais igual, mais justo e mais humano. Sem pretendermos ser performativos - um dos grandes defeitos da produção acadêmica -, sugerimos linhas de reflexão e ação, desafios e compromissos políticos, que possam abrir caminhos para profundas mudanças sociais.

\section{Notas}

1 O conceito de colonialidade do poder, de A. Quijano, e adotado por Mignolo e pelo grupo de estudos pós-coloniais, é inerente ao colonialismo e a todos os processos de colonização, interferindo em todas as esferas da atividade humana. Configura o modelo epistemológico dominante, os valores da cultura eurocêntrica e impostos aos povos subalternizados, dominados e suas culturas, a organização das mentes, o modo de pensar e a lógica que lhes está subjacente e ainda as relações de trabalho e intersubjetivas. O conceito de colonialidade não é derivante da modernidade, mas a sua face oculta. Modernidade e colonialidade são as duas faces da mesma moeda. Colonialidade e colonialismo são dois conceitos que se relacionam mas que, simultaneamente, se distinguem. O colonialismo é mais antigo do que 
a colonialidade mas esta, por sua vez, "provou ser, nos últimos 500 anos, mais profunda e duradoura do que o colonialismo.” (QUIJANO, 2007, p. 93)

2 De acordo com Canclini (2008, p. XIX) hibridação é "um conjunto de processos socioculturais nos quais estruturas ou práticas discretas, que existiam de forma separada, se combinam para gerar novas estruturas, objetos e práticas.” Considera o autor que as estruturas denominadas discretas foram, elas próprias, o resultado de hibridações e, por isso, não poderão ser consideradas fontes puras. Canclini parte do pressuposto de que, em nenhum momento histórico, existiram culturas puras.

3 José Carlos Mariátegui (1894-1930) foi escritor, jornalista, sociólogo, fundador do Partido Comunista Peruano, ativista político, a quem se devem estudos importantes sobre a realidade latino-americana e, especialmente, peruana, a partir das perspectivas marxistas. De etnia quéchua, fundamenta o seu pensamento em Gramsci, G. Lukács e W. Benjamín. Na sua obra, 7 Ensayos de interpretación sobre la realidad peruana, defende a tese de que o problema dos indígenas está indissoluvelmente ligado à questão agrária. Responsabiliza os proprietários agrários pela situação económica do país e pelas condições miseráveis em que viviam os indígenas. Referindo-se à sociedade peruana falava do pecado original da conquista como "o pecado de ter nascido e ter-se formado sem o índio e contra o índio.”(Apud SANTOS, 2010, p. 29).

4 "Las estrategias y políticas adoptadas para gobernar o administrar los problemas de la diversidad y la multiplicidad en los que se ven envueltas las sociedades multiculturales" con su variedad de distinciones: conservador, liberal, pluralista, comercial, corporativa y críticaradical (HALL, 2010, p. 583).

5 El multiculturalismo conservador sigue a Hume (Goldberg 1994) porque insiste en la asimilación de la diferencia a las tradiciones y costumbres de la mayoría. El multiculturalismo liberal busca integrar a los diferentes grupos culturales lo más rápidamente posible dentro de lo establecido por una ciudadanía individual universal, que sólo en privado tolera ciertas prácticas culturales peculiares. El multiculturalismo pluralista respalda formalmente las diferencias entre grupos a lo largo de líneas culturales y otorga distintos derechos grupales a distintas comunidades dentro de un orden político más comunitario o comunitarista. El multiculturalismo comercial presupone que, si el mercado reconoce la diversidad de individuos provenientes de comunidades diferentes, entonces los problemas de la diferencia cultural serán (di)(re)sueltos a través del consumo privado, sin necesidad alguna de una redistribución del poder y los recursos. El multiculturalismo corporativo (público o privado) busca "administrar" las diferencias culturales de las minorías en interés o beneficio del centro. El multiculturalismo crítico o "revolucionario" destaca el poder, el privilegio, la jerarquía de las opresiones y los movimientos de resistencia (MCLAREN 1997). Busca ser "insurgente, polifónico, heteroglósico y antifundacional” (GOLDBERG, 1994). Y así, sucesivamente. (HALL, 2010, p. 584).

6 En el contexto de países occidentales como los Estados Unidos, donde las minorías nacionales (negros e indígenas) coexisten con varios grupos de inmigrantes, minorías involuntarias como los puertorriqueños y chicanos, y los blancos, todos descendientes de otros países principalmente europeos; o como en Europa donde la inmigración se ha ampliado recientemente. 
7 Un intercambio que se construye entre personas, conocimientos, saberes y prácticas culturalmente distintas, buscando desarrollar un nuevo sentido de convivencia de éstas en su diferencia.

- Un espacio de negociación y de traducción donde las desigualdades sociales, económicas y políticas, y las relaciones y los conflictos de poder de la sociedad no son mantenidos ocultos sino reconocidos y confrontados.

- Una tarea social y política que interpela al conjunto de la sociedad, que parte de prácticas y acciones sociales concretas y conscientes e intenta crear modos de responsabilidad y solidaridad.

- Una meta por alcanzar (WALSH, 2005, pp. 10-11).

8 A diferença colonial é entendida como forma de pensamento a partir das ruínas, das experiências e das margens criadas pela colonialidade do poder na estruturação do mundo moderno/colonial, como forma não de restituir conhecimento, mas de reconhecer conhecimentos "outros" em um horizonte epistemológico transmoderno, ou seja, construído a partir de formas de ser, pensar e conhecer diferentes da modernidade europeia, porém em diálogo com esta. A perspectiva da diferença colonial requer um olhar sobre enfoques epistemológicos e sobre as subjetividades subalternizadas e excluídas. Supõe interesse por produções de conhecimento distintas da modernidade ocidental. Diferentemente da pós-modernidade, que continua pensando tendo como referência o ocidente moderno, a construção de um pensamento crítico "outro", parte das experiências e histórias marcadas pela colonialidade. (Cf. MIGNOLO, 2003; CANDAU; OLIVEIRA, 2010, p. 24).

\section{Referências}

CANDAU, Vera. Diferenças culturais, cotidiano escolar e práticas pedagógicas. Currículo sem Fronteiras, v. 11, n. 2, jul./dez. 2011, pp.240-255.

CANDAU, Vera. Direitos humanos, educação e interculturalidade: as tensões entre igualdade e diferença. Revista Brasileira de Educação, v. 13, n. 37 jan./abr., pp. 44-57, 2008.

CANDAU, Vera; OLIVEIRA, Luis Fernandes. Pedagogia decolonial e educação antirracista e intercultural no Brasil. Educação em Revista, v. 26, n. 01, p. 15-40, 2010.

CANCLINI, Nestor Garcia. Culturas híbridas. Estratégias para entrar e sair da modernidade. São Paulo: Edusp, 2008.

DALE, Roger. Globalização e educação: demonstrando a existência de uma cultura global comum ou localizando uma agenda globalmente estruturada para a educação? Educação, Sociedade e Culturas. Porto, n. 16, p. 133-169, 2001.

FANON, Franz. Los condenados de la tierra. México: Fondo de Cultura Económica, 2001.

FOURNET-BITTENCOURT, Raul. Interculturalidade. Rio de Janeiro: Nova Harmonia, 2004.

FREIRE, Paulo. Educação como prática da liberdade. São Paulo: Paz e Terra, 2006.

FREIRE, Paulo. Pedagogia da autonomia. Rio de Janeiro: Paz e Terra, 2015.

FREIRE, Paulo. Pedagogia do oprimido. Rio de Janeiro: Paz e Terra, 1987. 
HALL, Stuart. Sin garantías: trayectorias y problemáticas en estudios culturales. Quito: Envión Editores, 2010.

MALDONADO-TORRES, Nelson. Sobre la colonialidad del ser: contribuciones al desarrollo de un concepto. In: CASTRO-GÓMEZ, S.; GROSFOGUEL, R. (Org.) El giro decolonial. Reflexiones para una diversidad epistémica más allá del capitalismo global. Bogotá: Universidad Javeriana-Instituto Pensar, Universidad Central-IESCO, Siglo del Hombre Editores, p. 127-167, 2007.

MIGNOLO, Walter. Histórias Globais/projetos Locais. Colonialidade, saberes subalternos e pensamento liminar. Belo Horizonte: Editora UFMG, 2003.

QUIJANO, Anibal. QUIJANO, Aníbal. Colonialidad del poder y clasificación social. In: CASTROGÓMEZ, S.; GROSFOGUEL, R. (Org.). El giro decolonial. Reflexiones para una diversidad epistémica más allá del capitalismo global. Bogotá: Universidad JaverianaInstituto Pensar, Universidad Central-IESCO, Siglo del Hombre Editores, 2007. p. 93-126.

SANTOS, Boaventura de Sousa. Por uma Concepção Multicultural dos Direitos Humanos. Revista Critica de Ciências Sociais, n. 48, pp. 11-32, 1997.

SANTOS, Boaventura de Sousa. Dilemas do nosso tempo: globalização, multiculturalismo e conhecimento. Entrevista com Boaventura de Sousa Santos por Luis Armando Gandin e Álvaro Moreira Hypolito. Currículo sem Fronteiras, v. 3, n. 2, p.5-23, jul./dez. 2003.

SANTOS, Boaventura de Sousa. (Org.). Reconhecer para libertar. Os caminhos do cosmopolitismo multicultural. Porto: Edições Afrontamento, 2004.

SANTOS, Boaventura de Sousa. Refundación del Estado en América Latina. Perspectivas desde una Epistemología del Sur. Buenos Aires: Antropofagia, 2010.

TEODORO, António. Globalização e Educação. Políticas educacionais e novos modos de governação. Porto: Afrontamento, 2003.

WALSH, C. Significados y políticas conflictivas. Revista Nueva Sociedad (Caracas), 165, enero-febrero, pp. 121-133, 2000.

WALSH, C. La educación intercultural en la educación. Lima: Ministerio de Educación, Mimeografado, 2005.

WALSH, Catherine. Interculturalidad y colonialidad del poder. Un pensamiento y posicionamiento 'otro' desde la diferencia colonial. In: WALSH, C.; LINERA, A. G.; MIGNOLO, W. Interculturalidad, descolonización del estado y del conocimiento. Buenos Aires: Del Signo, 2006. p. 21-70.

WALSH, C. Etnoeducación e interculturalidad en perspectiva decolonial. Cuarto Seminario Internacional "Etnoeducacion e Interculturalidad. Perspectivas Afrodescendientes. Lima, 2012.

WALSH, C. Interculturalidad y (de) colonialidad. Perspectivas críticas y políticas. Visão Global, Joaçaba, v. 15, n. 1-2, p. 61-74, jan./dez. 2012.

WALSH, C. Pedagogías Decoloniales. Prácticas insurgentes de resistir, (re)existir y (re) vivir. Quito: Ediciones Abya-Ayala, 2013.

WALSH, C. Lo pedagógico y lo decolonial: entretejiendo caminos. Quito: Qurétaro, 2014. 
WALSH, C. Sobre el género y su modo-muy-otro. In: QUINTERO, P. Alternativas descoloniales al capitalismo colonial/moderno (165-182). Buenos Aires: Ediciones del Signo, 2015.

WALSH, Catherine. Entretejiendo lo pedagógico y lo decolonial: luchas, caminos y siembras de reflexión-acción para resistir (re) existir y (re) vivir. Alter/nativas. E-Book, 2017.

recebido em 3 mai. 2018 / aprovado em 26 jun. 2018

Para referenciar este texto:

TAVARES, Manuel.; GOMES, S. R. Multiculturalismo, interculturalismo e decolonialidade: prolegômenos a uma pedagogia decolonial. Dialogia, São Paulo, n. 29, p. 47-68, mai./ago. 2018. Disponível em: <https://doi.org/10.5585/Dialogia.n29.8646>. 